\title{
Primary visual cortex is necessary for blindsight-like behavior in neurologically healthy individuals: Review of transcranial magnetic stimulation studies
}

\author{
Henry Railo $1,2,3$ and Mikko Hurme ${ }^{2,3}$ \\ ${ }^{1}$ Department of Clinical Neurophysiology, University of Turku, Turku, Finland \\ 2 Turku Brain and Mind Centre, University of Turku, Turku, Finland \\ 3 Department of Psychology, University of Turku, Turku, Finland
}

\begin{abstract}
The visual pathways that bypass the primary visual cortex (V1) are often assumed to support visually guided behavior in humans in the absence of conscious vision. This conclusion is largely based on findings on patients: V1 lesions cause blindness but sometimes leave some visually guided behaviors intact - this is known as blindsight. With the aim of examining how well the findings on blindsight patients generalize to neurologically healthy individuals, we review studies which have tried to uncover transcranial magnetic stimulation (TMS) induced blindsight. In general, these studies have failed to demonstrate a completely unconscious blindsight-like capacity in neurologically healthy individuals. A possible exception to this is TMS-induced blindsight of stimulus presence or location. Because blindsight in patients is often associated with some form of introspective access to the visual stimulus, and may be associated with neural reorganization, we suggest that rather than revealing a dissociation between neural mechanisms of behavior and conscious seeing, blindsight may reflect preservation or partial recovery of conscious visual perception after the lesion.
\end{abstract}

Key words: blindsight, transcranial magnetic stimulation, lesion, unconscious perception

\section{Introduction}

Blindsight patients have visual field defects due to a visual cortical lesion, but paradoxically, they can use stimuli in the blind visual field to guide their behavior (Cowey, 2010; Pöppel, Held, \& Frost, 1973; Sanders, Warrington, Marshall, \& Wieskrantz, 1974; Weiskrantz, Warrington, Sanders, \& Marshall, 1974). Blindsight is interesting because, first, it suggests that stimuli that are not consciously seen can be used to guide behavior. Second, this ability to use unconscious visual information to guide behavior may not depend on the primary visual cortex (V1), whereas conscious vision does depend on it. However, although these conclusions are currently widely accepted, little is known about how well this phenomenon can be generalized to neurologically healthy individuals. Does a similar unconscious blindsight-like capacity influence the behavior of neurologically healthy individuals? This is an interesting question not only from the perspective of basic science and consciousness research, but also because it may also offer insights into the recovery of vision after lesions (Das, Tadin, \& Huxlin, 2014; Melnick, Tadin, \& Huxlin, 2016).

The present article has three aims. First, after briefly introducing blindsight, we will argue that to understand blindsight and its neural basis, it needs to be compared to neurologically healthy control participants. Second, we review studies that have examined whether a blindsight-like capacity can be observed in neurologically healthy individuals when transcranial magnetic stimulation (TMS) is used to interfere with the activity in the visual cortex. Third, after concluding that there is little evidence for strictly unconscious blindsight-like behavior in neurologically healthy participants, we propose that blindsight indicates either preservation or partial recovery of conscious vision after the lesion. We also briefly discuss key topics such as the challenges in 
measuring conscious perception, and basics of TMS - readers who are familiar with these topics may want to skip these.

\section{Blindsight in patients}

\subsection{What is blindsight?}

We use the term blindsight to refer to the capacity of patients with cortical blindness following damage to the visual cortex to use information from visual stimuli presented to their clinically blind field to guide behavior (Danckert et al., 2019). More specifically, we assume that blindsight is always accompanied by a lesion to the $\mathrm{V} 1$ although the lesion does not have to be restricted to only the V1. We use the term "conscious" vision to refer to visual perception that is accompanied by experiences that can be introspected by the subject. We use "unconscious" visual perception to refer to situations where the stimuli that the subject denies consciously seeing can nevertheless influence their behavior in some way.

The phenomenon of blindsight has been widely documented (Stoerig \& Cowey, 1997). Indeed, patients who report not consciously seeing stimuli because of the cortical lesion have been shown to detect (Ajina et al., 2015a; Azzopardi \& Cowey, 1997) and localize (de Gelder et al., 2008; Weiskrantz et al., 1974; Zihl, 1980) objects, discriminate motion direction (Ajina \& Bridge, 2018; Azzopardi \& Cowey, 2001; Blythe et al., 1986; Pavan et al., 2011; Perenin, 1991), color (Stoerig, 1987; Stoerig \& Cowey, 1992), and shape (Marcel, 1998), and process the affective information (De Gelder et al., 1999; Striemer et al., 2019) of stimuli presented to the blind visual field. Blindsight can also be measured by examining how stimuli presented to the blind visual field modulate manual reaction times (Marzi et al., 1986; Tamietto et al., 2010) or eye movements (Rafal et al., 1990; Savina \& Guitton, 2018) to stimuli presented to the intact visual field.
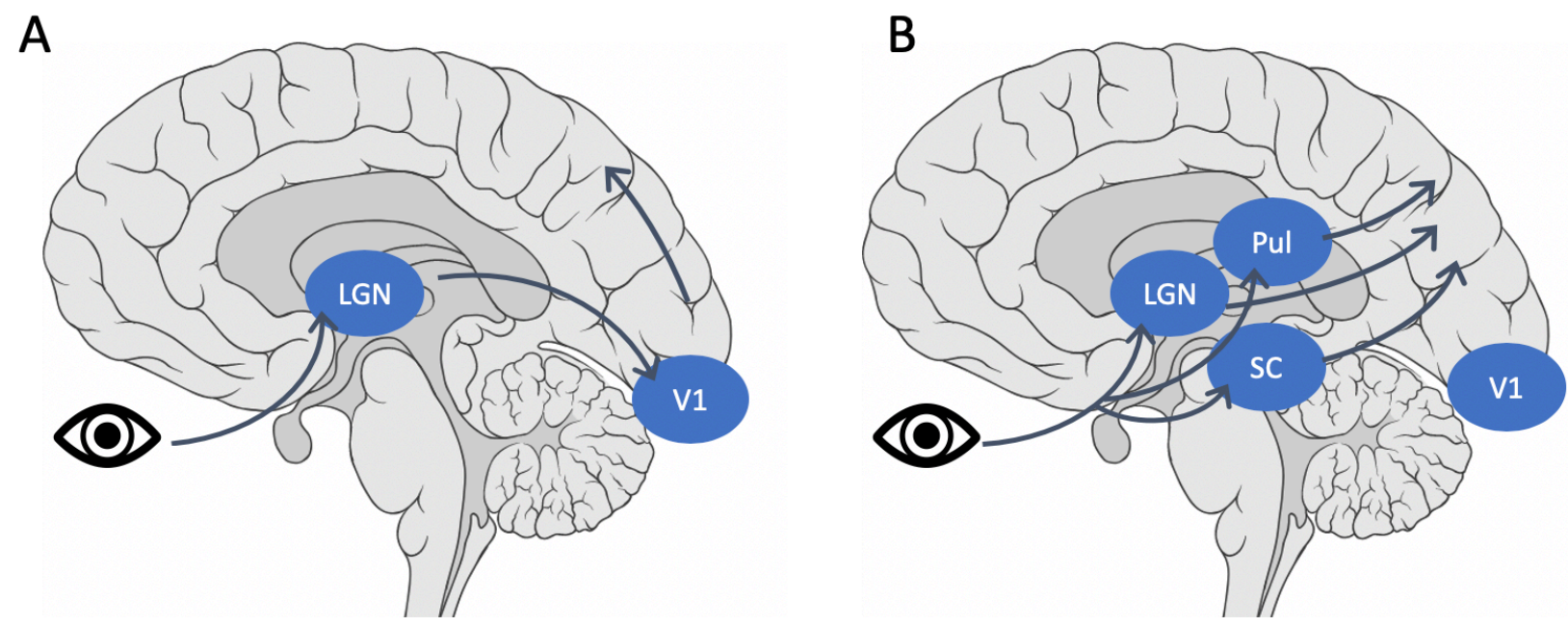

Figure 1. Schematic of the pathways that relay visual information from the retina to the cortex. A) The geniculo-striate pathway is the major visual pathway that is lesioned in blindsight patients. B) When the V1 is lesioned, other pathways may relay visual information to the cortex and support visually guided behavior. $\mathrm{V} 1=$ primary visual cortex, $\mathrm{LGN}=$ lateral geniculate nucleus of the thalamus, Pul $=$ Pulvinar, $\mathrm{SC}=$ superior colliculus. [Brain image credits: Patrick J. Lynch \& Carl Jaffe.] 


\subsection{Pathways to blindsight}

To explain blindsight, researchers have tried to characterize the pathways through which information from the eyes could be passed to the cortex without the V1. These studies have typically relied on nonhuman primate or rodent models. In addition to projecting to the V1 (Fig. 1A), neurons in the LGN project to other visual cortical areas (called "extrastriate" areas) such as the V2 (Bullier \& Kennedy, 1983; Markov et al., 2011; Yukie \& Iwai, 1981), V3 (Benevento \& Yoshida, 1981), V4 (Benevento \& Yoshida, 1981; Gattass et al., 2014; Lyon \& Rabideau, 2012), and MT+/V5/MT (Jayakumar et al., 2013; Lyon \& Rabideau, 2012; Sincich et al., 2004). These projections (Fig. 1B) are one major class of candidate pathways that can explain blindsight. Schmid et al. (2010) demonstrated in macaque monkeys with V1 lesions that reversible inactivation of the LGN eliminated behavioral detection and visual cortical responses to stimuli presented in the blind visual field, suggesting that LGN causally mediates blindsight. Especially the projections from the LGN to the MT+/V5 are assumed as being crucial for blindsight (Bridge et al., 2010; Bridge et al., 2008; Goebel et al., 2001).

One major visual pathway goes through the pulvinar (Baldwin et al., 2017), which receives direct input from the eyes (Cowey et al., 1994; Nakagawa \& Tanaka, 1984; O'Brien et al., 2001). The retina also projects to SC (Crook et al., 2008; Perry \& Cowey, 1984; Schiller \& Malpeli, 1977), which then projects to cortical areas V3 and MT+/V5/MT through the LGN and pulvinar (Lin \& Kaas, 1979; Lyon et al., 2010). This pathway is involved in relaying low-contrast, quickly moving visual information to the cortex (Lyon \& Rabideau, 2012). According to one model, the SC relays affective information to the amygdala, enabling rapid responses to threatening stimuli through what is commonly referred to as the "low-road" visual system (LeDoux, 2012; Öhman \& Mineka, 2001; Tamietto \& De Gelder, 2010; but for critique, see Pessoa \& Adolphs, 2010). Most direct evidence for the involvement of the SC-pulvinar pathway in blindsight comes from studies in monkeys (Kinoshita et al., 2019). Neuroimaging studies have shown that SC is activated during blindsight in humans (Celeghin et al., 2019; Tamietto et al., 2010). However, it is difficult to know whether this activation in humans reflects bottom-up visual input from retina, or feedback from subcortical or cortical areas.

\subsection{Beyond feedforward pathways}

The idea that feedforward pathways to cortex alone explain blindsight may be too simplistic because brain areas form complex, interconnected networks rather than simple serial signaling pathways (Buzsaki, 2019; Pessoa, 2014). In addition to disrupting feedforward pathways, lesions interrupt feedback processes. This may modify how e.g., visually evoked activation spreads. For example, only approximately $5 \%$ of neurons in the V1 receive direct input from the LGN (Douglas \& Martin, 2007). Similarly, activity in the V1 is strongly influenced by back-projections from cortical and subcortical areas (Muckli \& Petro, 2013). The LGN receives only approximately 10\% of its input from the retina, whereas about $30 \%$ of the input comes from back-projections from the V1 (Ghodrati et al., 2017; Sherman \& Guillery, 2002). Similarly, the majority of inputs to the pulvinar comes from the cortex (Shipp, 2003), and SC receives massive input from the V1 and various other cortical and subcortical areas (Basso \& May, 2017). This means that lesions to V1 may modulate the spread of visual information in a complex manner (Muckli \& Petro, 2013; Sillito et al., 2006). For example, White et al. (2017) showed that although visual saliency representation emerges earlier in SC than in the V1, visual activation latencies were shorter in the V1, suggesting that the saliency representation in SC may depend on inputs from the V1. Consequently, lesions to V1 may also strongly affect the processing of distant areas, possibly changing their functional roles. Consistent with this, in blindsight patients, responses in V5/MT + to stimuli presented to the blind 
visual field change (when compared to healthy controls), possibly because dominant input from V1 is removed (Ajina, Kennard, Rees, \& Bridge, 2015; Ajina, Rees, Kennard, \& Bridge, 2015). Cortically blind patients also show perceptual deficits in their "intact" visual field (Bola, Gall, \& Sabel, 2013), suggesting changes in modulatory activity. Altogether these factors imply that blindsight, as observed in patients, may not straightforwardly generalize to neurotypical individuals.

\subsection{How blind is blindsight?}

A major question is whether blindsight is degraded and partially conscious vision rather than a separate unconscious capacity (Campion, Latto, \& Smith, 1983; Phillips, 2020). To measure conscious perception, participants need to report what they perceive. The simplest approach is to use a binary scale: the participant rates something as "seen" or "not seen" (Fig. 2A). Problem with this approach is that it does not capture the graded nature of conscious perception, which is why rating scales with more alternatives should be used (Fig. 2B) (Overgaard, Rote, Mouridsen, \& Ramsøy, 2006; Ramsøy \& Overgaard, 2004; Sandberg, Timmermans, Overgaard, \& Cleeremans, 2010). Furthermore, it is important to realize that blindsight-like dissociation can be observed simply because the means of measuring behavior may be more sensitive than the method used to measure conscious perception (Campion et al., 1983) (Fig. 2C-D).

A

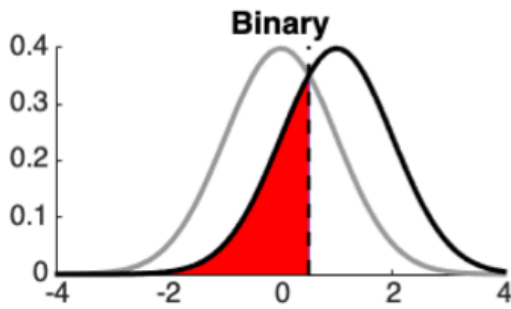

C

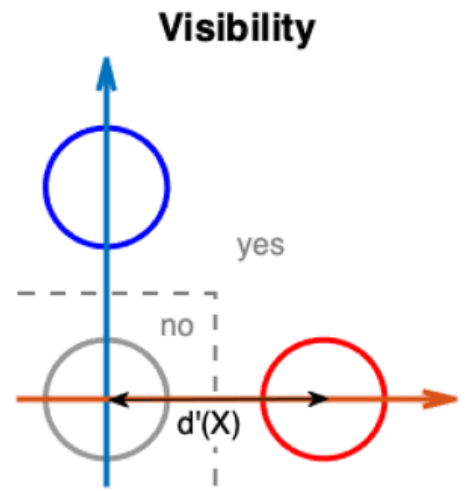

B

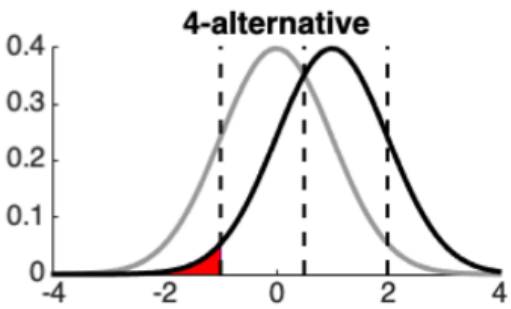

D

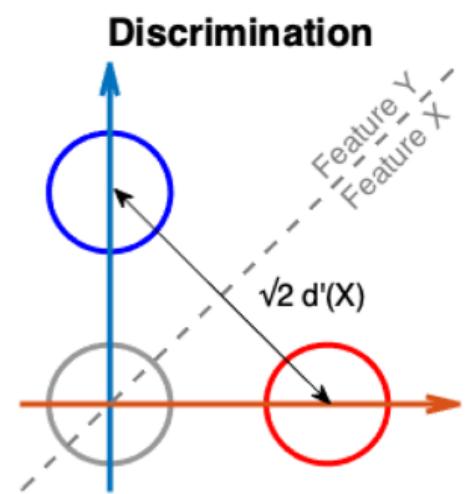

Figure 2. The signal detection theoretic (SDT) perspective into detecting and discriminating stimuli. A) According to the SDT, perception is a noisy process where the aim is to distinguish a signal (e.g., the visual stimulus; black line) from noise in the system (gray line). The participant compares the strength of internal response (x-axis) to some criterion (dashed line). If the internal response exceeds the criterion, she or he reports that the stimulus was present. When only one criterion is used, stimuli with a relatively high signal strength may be classified as "not seen" (red area). B) Evidence can be reported with more detail with more alternatives. The two lower panels compare visual detection (C) and discrimination (D) tasks (e.g., left vs. right stimulus, here represented as blue and red axes when viewed from above). The task of discriminating two features (D) may be more sensitive than the task where signals are labelled "seen" vs. "not seen"(C). For more details, see (King \& Dehaene, 2014; Ko \& Lau, 2012). 
Blindsight patients often deny that they see anything in their scotoma. For instance, a patient tested by Pöppel et al. (1973) asked, "How can I look at something that I haven't seen?" (p. 295) when asked to try to fixate a target presented in the scotoma. However, because many studies on blindsight patients have not employed systematic, trial-by-trial investigations of visual experiences during the visual task, it is unclear how many instances of reported unconscious capacity are merely severely degraded conscious vision (see also, Mazzi, Savazzi, \& Silvanto, 2019; Overgaard, 2011). Studies by Overgaard et al. (2008) and Mazzi et al. (2016) show that what may be initially interpreted as unconscious perception may just be degraded conscious vision, when visibility is measured with graded scales. It is also well known that cortically blind patients report conscious perception especially when moving stimuli are used (Ffytche \& Zeki, 2011; Riddoch, 1917).

Blindsight is often divided into type- 1 and type- 2 forms. Type-1 blindsight refers to truly unconscious blindsight cases where the patients are not assumed to be able to consciously introspect any information related to the stimulus presented to the scotoma. Type- 2 blindsight refers to cases where the patients have some introspective access to the information about stimuli in the scotoma. Type-2 experiences are assumed to be "non-visual". For example, when pressed, patient D.B. reported that he "had a 'feeling' that the stimulus was either pointing this or that way, or was 'smooth' (the O) or 'jagged' (the X)" (p. 721) (Weiskrantz et al., 1974). Although some blindsight cases may be better characterized as very degraded conscious vision, and accompanied by type-2 "feelings" accessible to introspection, studies suggest that blindsight is nevertheless different from normal conscious vision (Azzopardi \& Cowey, 1997; Trevethan, Sahraie, \& Weiskrantz, 2007; Larry Weiskrantz, 2009; Lawrence Weiskrantz, Cowey, \& Hodinott-Hill, 2002). This suggests that neural plasticity may play a role in shaping blindsight.

\section{Mimicking blindsight with TMS}

\subsection{The need for control participants}

To what extent is blindsight-like capacity present in neurologically healthy individuals? Researchers often assume that blindsight reveals a hardwired capacity that is also functional in neurologically healthy individuals. This reasoning is based on the assumption that a cortical lesion eliminates a specific functional capacity (e.g., conscious vision mediated by V1), without affecting others (e.g., visually guided behavior mediated by V1-bypassing pathways). However, as argued above, visual cortical lesions could lead to complex changes in how networks of areas process visual information, possibly enabling visual abilities that do not exist in neurologically healthy individuals. Neural reorganization following the lesion may further modify how cortically blind patients process information. To understand to what extent blindsight-like behavior is present in neurologically intact individuals, neurologically healthy control participants are needed.

Some findings suggest that blindsight may not generalize to neurologically healthy individuals. For instance, widely-studied patient G.Y. explains in an interview how he gradually learned to use information from the blind field to guide his behavior: "I'd walk into a lamp post or into a bin. I just didn't see it, I'd walk straight into it, and that doesn't happen anymore" (Heron, 2000). Importantly, the connectivity of circuits that survived the lesion clearly differs from neurological healthy humans in G.Y. (Bridge et al., 2008; Silvanto, Walsh, \& Cowey, 2009; Tamietto, Pullens, De Gelder, Weiskrantz, \& Goebel, 2012). Similarly, monkeys do not reveal blindsight immediately after a visual cortical lesion (Humphrey, 1972; Humphrey \& Weiskrantz, 1967). This suggests that blindsight may require neural reorganization to develop, implying that neurologically healthy humans should not reveal a similar capacity. 
Alternatively, it could be argued that blindsight may not be present right after the lesion during the acute period because it takes time for the system to recover some of its normal functioning. Furthermore, blindsight may not be observed in cortically blind patients if the damage extends to the V1-bypassing pathways and cortical areas that are assumed to mediate blindsight. Consistent with this interpretation, those cortically blind patients who display blindsight have comparable anatomical (Ajina, Pestilli, Rokem, Kennard, \& Bridge, 2015b) and functional (Ajina \& Bridge, 2018) connectivity between LGN and V5/MT+ as healthy controls. According to this interpretation, neurologically healthy humans should show a similar blindsight capacity as some patients. Arguably, neurologically healthy humans could even display stronger forms of blindsight than patients because patients often have lesions affecting other areas than the V1.

Next, we discuss how TMS offers means to study if V1-bypassing pathways enable blindsight-like behavior in neurologically healthy individuals.

\subsection{TMS basics}

Cortical neurons can be stimulated by inducing an electric field (E-field) into the cortex using TMS (Figure 3). With neuronavigated TMS, individual cortical areas can be targeted, but because the induced E-field depends on multiple factors (including cortical folding, coil type, and stimulation intensity, Thielscher et al., 2011; Weise et al., 2020), targeting specific cortical areas is very difficult. For example, the visual areas V2/V3 are often closer to the surface of the head than the V1, making selective stimulation of the V1 difficult. Based on TMS-induced E-fields that are estimated using a spherical volume conductor model, selective stimulation of the V1 can be obtained in a subset of individuals when retinotopically mapped visual areas are available (Salminen-Vaparanta et al., 2012). When no retinotopic images of visual areas are available, the location of the V1 can be accurately predicted from cortical folding: it is in the calcarine sulcus (e.g., upper visual left field is represented in the lower bank of the calcarine sulcus in right hemisphere)(Henriksson et al., 2012; Hinds et al., 2008). This means that TMS pulses can be directed at the V1 based on anatomical images (although adjacent areas such as the V2 and V3 are also stimulated). When no anatomical brain images are available, TMS is simply aimed at locations that influence visual perception, but there is no guarantee that the V1 will be stimulated.

Contralateral occipital stimulation disturbs conscious vision: the participant's vision becomes blurred in the stimulated visual field location, and sometimes, the stimulus is not consciously seen at all (Amassian et al., 1989). This finding is visualized in Figure 3E. The suppressive effect is strongest when the stimulus onset asynchrony (SOA) between the visual stimulus and the TMS pulse onset is around 80-120 ms. Note that a demonstration that TMS to V1 eliminates unconscious visual processing at any SOA would be at odds with findings in patients because a lesion prevents processing in V1 at all times. Blindsight is therefore by definition V1independent.

\section{Review of TMS-induced blindsight studies}

We will next review studies that have used TMS to try to induce blindsight-like behavior in neurologically healthy participants. We searched PubMed for articles using the following search term: "((TMS) OR (transcranial magnetic stimulation)) AND ((blindsight) OR (unconscious))". The search yielded 155 articles. Only studies that used early visual cortical TMS were considered as being directly relevant. Based on reading the abstracts, 23 articles were included in the review. The reviewed studies are listed in Table 1. 


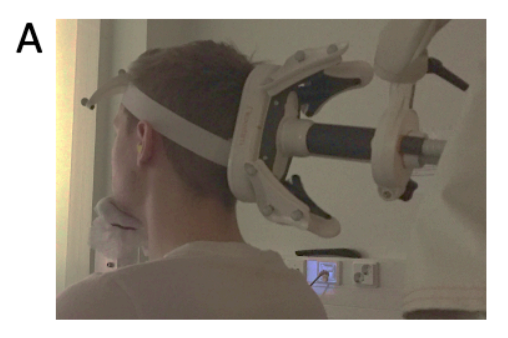

D

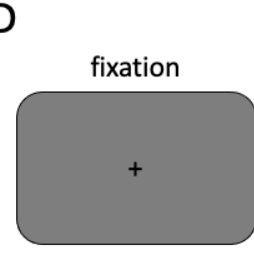

Target:

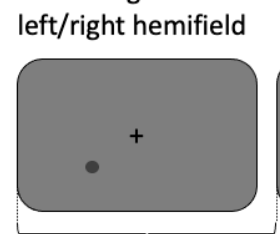

SOA

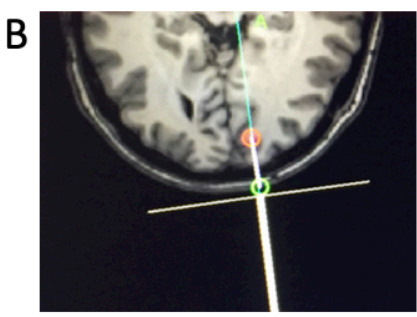

C

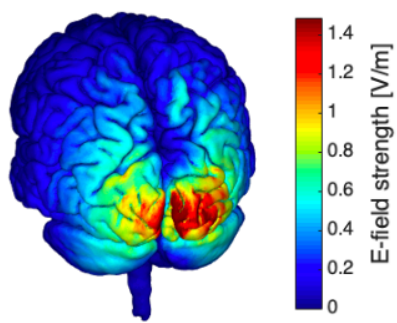

TMS: left/right hemisphere

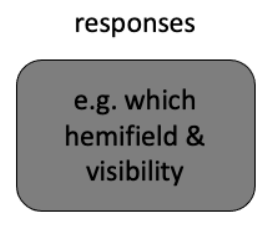

E

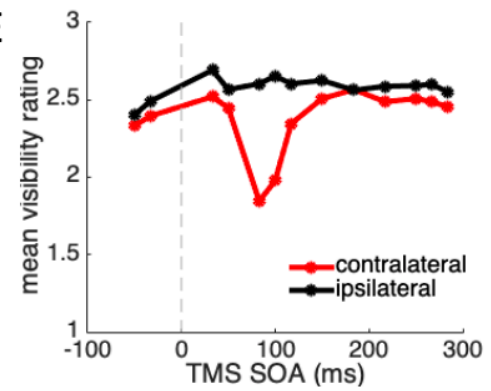

Figure 3. Transcranial magnetic stimulation (TMS). A) A coil is used to magnetically induce an Efield into the cortex. B) TMS can be targeted to specific cortical location based on brain images. C) The induced E-field is strongest right below the coil but also affects nearby areas (visualization done using SimNIBS (Saturnino et al., 2019)). D) In TMS-blindsight experiments, TMS pulses are often triggered at specific temporal intervals relative to a visual stimulus (SOA $=$ visual stimulus vs. TMS pulse onset asynchrony). E) When TMS is applied to, for example, the left visual cortex, the contralateral (right) visual field is affected. Stimuli presented to the ipsilateral visual field can serve as control stimuli (data from Railo \& Koivisto (2012)).

In the following chapters, we review the TMS studies by grouping them according to the visual features that the participants based their responses on. This was motivated by the fact that the processing of different visual features is based on different pathways/areas. For example, whereas the pathway through SC could be argued as supporting the localization of luminance-defined stimuli, it is less likely that such a pathway would support the discrimination of shapes or color because of the large non-color opponent receptive fields of SC neurons. Consequently, it is plausible to assume that in neurologically healthy humans, only specific types of stimuli/tasks allow for blindsight-like behavior. Similarly, different forms of blindsight in patients have been suggested to rely on different neural substrates and come in different forms (Celeghin et al., 2019; Danckert \& Rossetti, 2005).

A strong demonstration of TMS-induced blindsight requires showing that visual cortical activity has been disturbed by the TMS pulses to the degree that the participant reports not seeing it (as in cortical blindness). It is difficult to ascertain that TMS affected early visual cortical representation to a sufficient degree in studies that have used low-contrast stimuli or masking to reduce stimulus visibility. For this reason, we discuss these studies in a separate section (titled "Studies employing masked priming or low-contrast stimuli").

Rather than performing a meta-analysis, our aim here is to draw the reader's attention to the fact that methodological factors such as the means by which subjective perception has been measured, as well as the task-relevant stimulus feature may explain why studies have reached different conclusions. 


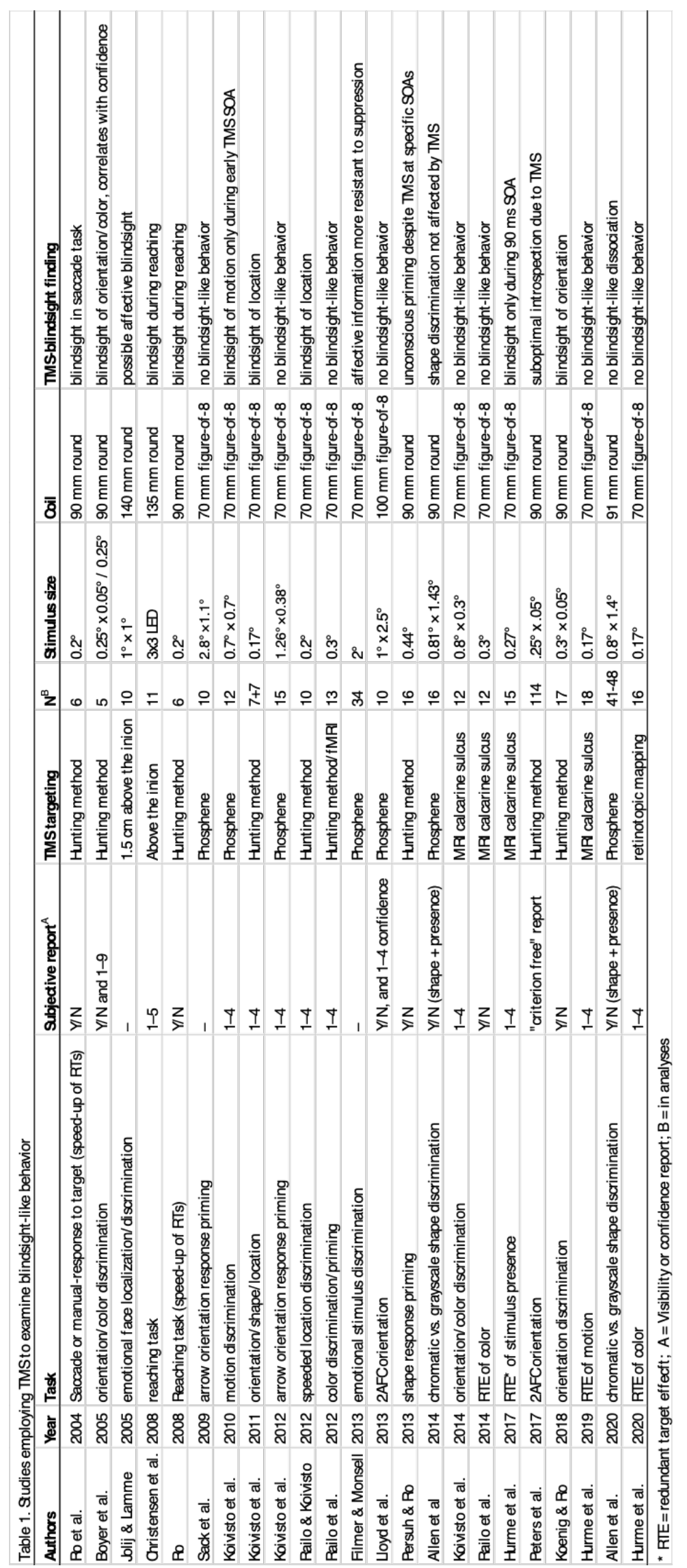




\subsection{Stimulus presence/location}

Ro et al. (2004) was the first to report TMS-induced blindsight, observing that distractor stimuli that the participants reported not seeing influenced the speed of eye movements toward a lateralized target. The authors did not observe a similar effect when the participants reported the location of the target with a manual button-press, based on which they argued that the effect was mediated by visual pathways through the SC. Later, using a similar distractor paradigm, Ro (2008) observed that it was possible to influence reaction times when a manual reaching task was used. Both of these studies (Ro et al., 2004; Ro, 2008) employed a binary yes/no visibility rating.

Christensen et al. (2008) reported that a TMS-suppressed distractor stimulus influenced hand-reaching movements even though "unconscious perception" was defined as the lowest alternative in a five-step visibility scale. Koivisto et al. (2011) primarily studied orientation versus shape processing, but the paradigm included a response procedure where the participants also reported the stimulus location (left vs. right visual field) when answering the orientation/shape question. Here, stimulus visibility was measured using a four-step scale. Location detection was significantly above chance, even when only the lowest visibility rating was examined. Railo and Koivisto (2012) showed that participants who reported not seeing a lateralized target stimulus at all (the lowest rating on a four-step scale) because of early visual cortex TMS could still correctly guess the side of the target with about $70 \%$ accuracy. Altogether, these studies indicate that participants can unconsciously process the rough location of a stimulus, even when V1 activity is disturbed with TMS to the degree that there is suppression of conscious vision (as measured by yes/ no or graded visibility reports).

The above studies did not examine if the effect of TMS on blindsight-like behavior varies when early visual cortical activity is interfered at different delays (i.e., SOAs; Fig. 3D). Studies on blindsight patients rely on anatomical "different pathway" explanatory models because in the patients, the lesion is always present. In contrast, because TMS pulses can be applied at different temporal intervals, they allow for the examination of physiological "same pathway" models, which attribute different functions to visual areas at different time points. The early bottom-up flow of visually evoked activity through the early visual cortex is assumed to be unconscious, but may have the capacity to influence behavior (Lamme \& Roelfsema, 2000; Vanrullen, 2007; VanRullen \& Koch, 2003). This feedforward stimulus-evoked activation in the V1 in humans occurs around 60 ms after stimulus onset (Foxe \& Simpson, 2002; Wilson et al., 1983).

Hurme et al. (2017) used the redundant target effect (RTE) to study TMS-induced blindsight. The RTE is a phenomenon where an additional stimulus speeds up reaction times, even though this "redundant" stimulus is not necessary for performing the task. In Hurme et al.'s study, "unconscious" was operationalized as follows: the participants reported being confident (highest rating on three alternative scale) in seeing one stimulus even though two were presented. The results showed that when the visibility of the redundant stimulus was suppressed by early visual cortex TMS at $60 \mathrm{~ms}$ SOA, RTE was eliminated. However, when conscious vision was suppressed at $90 \mathrm{~ms}$ SOA, a statistically significant RTE remained (Fig. 4A), showing that visually guided behavior was influenced by the unconscious stimulus. These results provide causal evidence for the idea that early feedforward responses are necessary for both unconscious and conscious vision, whereas later time windows contribute more to conscious vision. Of note is that this type of finding is at odds with blindsight observed in patients: In patients, the lesion is permanent, and hence both feedforward and feedback activity are prevented. 
We conclude that TMS studies provide evidence that information about the location or presence of a stimulus can guide participants' behavior, even when the participants report that they do not perceive the stimulus due to V1 TMS. In contrast to blindsight patients, this effect may be restricted to TMS suppression, where the initial feedforward sweep is not inhibited. However, a stringent psychophysical demonstration of TMS-induced blindsight (e.g., similar to Azzopardi \& Cowey, 1997, in patients) of stimulus presence/location is still lacking.

A

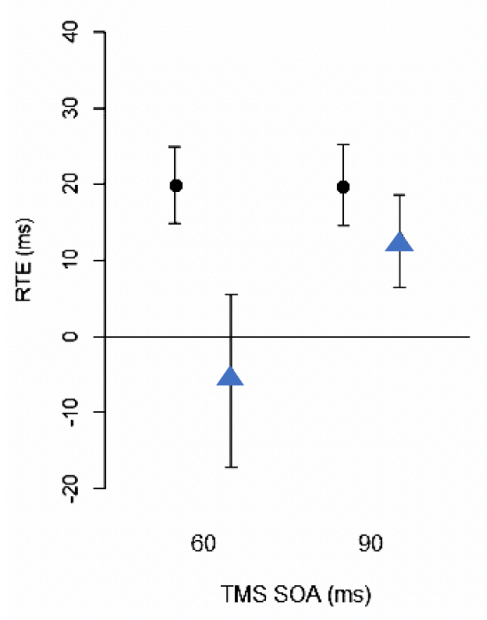

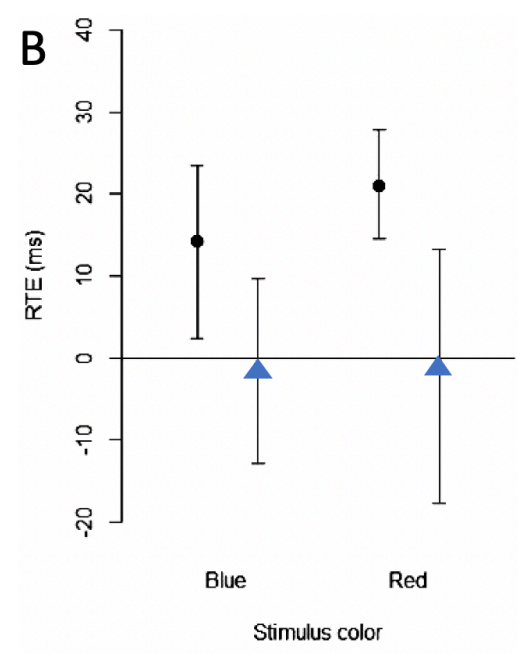

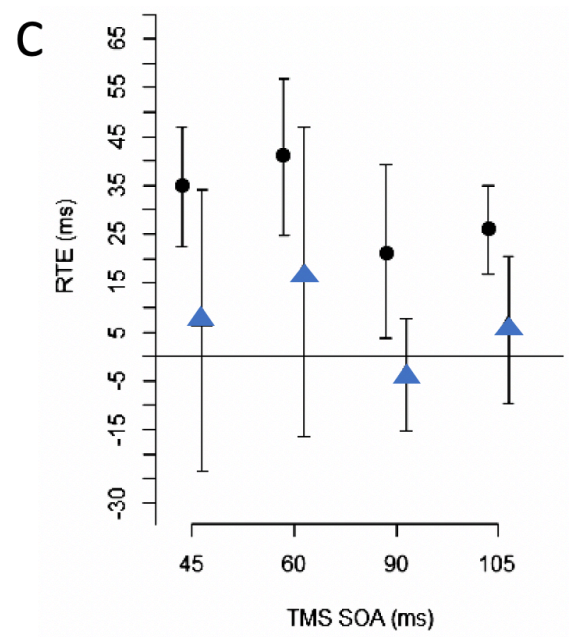

Figure 4. Results of TMS-induced blindsight studies employing the redundant target effect (RTE). The black dots represent the effect of the conscious redundant stimulus, and the blue triangles represent the effect of an unconscious (because of TMS to calcarine sulcus) redundant target on reaction times. The error bars are $95 \%$ confidence intervals. In all of these studies, an unconscious RTE was observed when the target was rendered unconscious by visual masking (i.e., when the V1 activity was not interfered with). A) RTE of stimulus presence: The participants were asked to make simple responses to targets. Unconscious RTE was observed in the $90 \mathrm{~ms}$ SOA (Hurme et al., 2017). RTEs produced by b) chromatic information (Hurme et al., 2020) or C) motion (Hurme et al., 2019) were not observed when the redundant target was unconscious because of TMS.

\subsection{Orientation}

Boyer et al. (2005) reported that orientation can be processed even when conscious vision is suppressed by early visual cortex TMS (see, (Koenig \& Ro, 2019) for a similar result). The target (a horizontal or vertical bar) was presented next to fixation, and the participants were asked whether they saw the orientation of the stimulus. If the participants reported being unconscious of the object's orientation, they were asked to give their best guess of the orientation and then asked to rate how confident they were about their response (on a scale of 1-9). Boyer et al. (2005) reported that the participants could report the orientation of the stimulus beyond the level of mere chance, even though they reported not seeing the orientation of the bar (shown in Figure 5A). However, the participants' confidence ratings correlated strongly with objective performance, indicating that the participants did have introspective access to the visual feature they were making judgments about. In fact, when the participants selected the highest confidence level, the accuracy was $100 \%$, as shown in Figure 5B. Moreover, it should be stressed that in the study by Boyer et al. (2005), the participants were not asked whether they did not see the stimulus, but they merely reported (using a binary scale) being not conscious of the specific visual feature they were asked to judge. It is likely that Boyer et al. (2005) measured near-threshold vision, not unconscious vision. 
Lloyd et al. (2013) used signal detection theoretic analyses to test whether a TMS-induced blindsight of orientation could be observed when a criterion-free measure of visual sensitivity is used. While replicating the original finding of Boyer et al. (2005), Lloyd et al. (2013) found no evidence that TMS-induced blindsight (as measured independently of a criterion) exits. This is shown in Figure 5C-D.

Peters et al. (2017) used a two-interval forced-choice paradigm that minimized the participants' need to specify a criterion for reporting conscious perception. TMS was applied on one of the intervals (SOA 100-128 ms), and in addition to reporting the orientation of the stimulus at each interval, the participants were asked to judge which of the two intervals contained a more visible target. As expected, objective sensitivity (d') was decreased by TMS relative to the no-TMS intervals. The authors also argued that they found evidence for TMS-induced blindsight because even when the participants' objective discrimination performance was at zero, they chose the TMSinterval as "more visible" at a rate that was higher than predicted by chance. Yet because TMS was only applied in one interval, the "more visible" reports could be because of, for example, perception of phosphenes, even if no stimulus was perceived.

We conclude that currently, there is little evidence for type-1 TMS-induced blindsight when the task requires processing the orientation of the stimulus.
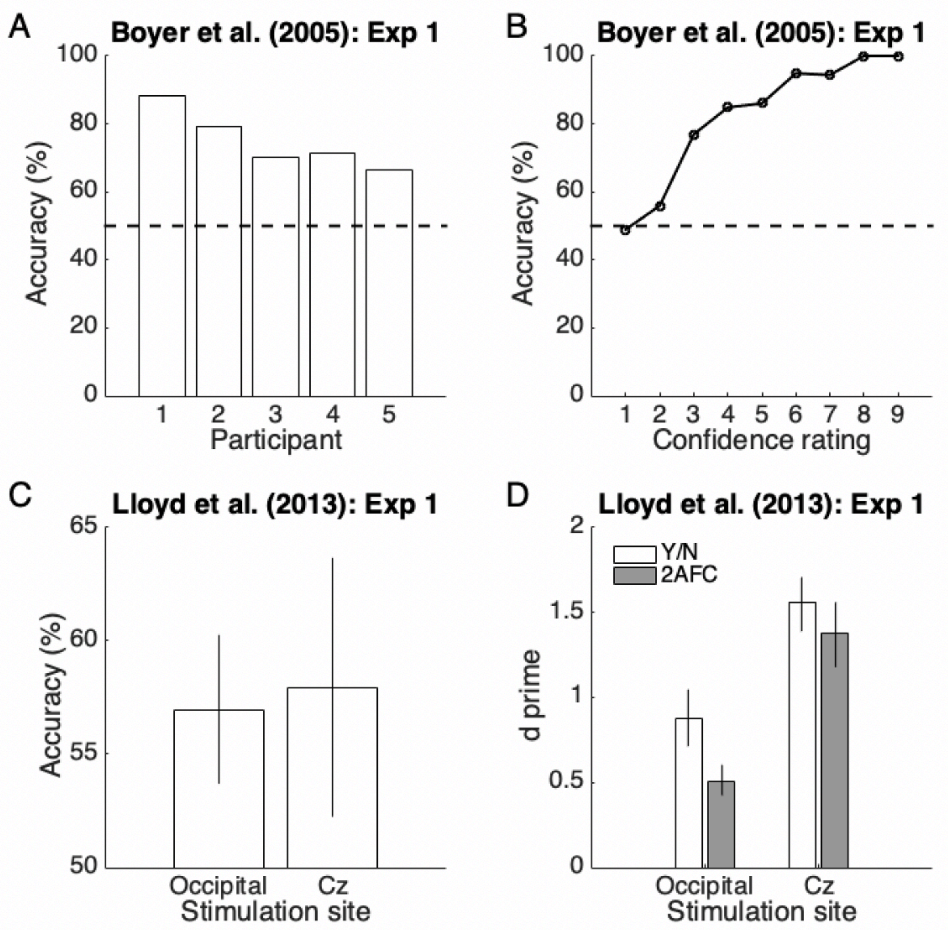

Figure 5. Effects of early visual cortex on orientation perception. A) Accuracy of visual discrimination when the participants reported not seeing the orientation of the stimulus in Boyer et al. (2005). B) The discrimination accuracy correlates strongly with confidence ratings, suggesting that the results reported by Boyer et al. are not unconscious vision but rather near-threshold vision. C) The accuracy of correctly reporting orientation when either the occipital cortex or control area $(\mathrm{Cz})$ is stimulated (form Lloyd et al. (2013), Experiment 1): the performance is above chance even when the occipital cortex is stimulated, thus replicating Boyer et al. D) However, visual sensitivity in the Yes/No and two-alternative forced-choice tasks in the two stimulation conditions shows no sign of a blindsight-like dissociation. (The figures are reproduced from original publications using WebPlotDigitizer (Rohatgi, 2015)) 


\subsection{Chromatic information}

In addition to examining the unconscious processing of orientation, Boyer et al. (2005) used the same paradigm to examine TMS-induced blindsight of chromatic information. The results are very similar to those observed with the orientation task: the participants could report the color of the stimulus with a relatively high-level accuracy (about 70-95\% correct) when they reported not seeing the target (yes/no rating). Furthermore, the participants' performance correlates with their confidence ratings, indicating that their responses were not based on completely unconscious information. As with orientation processing, the reported "unconscious" color processing is more likely degraded conscious vision.

Railo et al. (2012) examined the possibility of TMS-induced blindsight of chromatic information by using forced-choice judgments when stimulus visibility was measured using a fourstep scale. The results show that when the participants reported not seeing color but possibly still seeing a glimpse of stimulus presence, they could still discriminate color above guessing rate (66\% correct, $\mathrm{SD}=17 \%, \mathrm{n}=6$ ); this is consistent with the results by Boyer et al. (2005). The participants who reported being unconscious of the whole visual stimulus could not discriminate color above a typical guessing rate $(49 \%$, range $=37-60 \%, \mathrm{~N}=3)$. Although the sample in the final comparison is very small, the results suggest that the way "unconscious" vision is operationalized is important for how strong unconscious visual processing is observed.

Railo et al. (2014) and Hurme et al. (2020) examined the TMS-induced blindsight of chromatic information using the RTE paradigm but observed that the suppression of conscious vision also eliminated unconscious vision. The two studies were also specifically designed to reveal the contribution of SC using S-cone isolating stimuli and control L/M-cone stimuli, as has been reported in blindsight patients (Leh, Mullen, \& Ptito, 2006; Tamietto et al., 2010). However, no differences were found between different wavelength stimuli in either study (Hurme et al., 2020; Railo et al., 2014). The results of Hurme et al. (2020) are shown in Figure 4B.

Altogether, the data from these studies indicate that both the unconscious and conscious perception of color rely on the V1 in neurologically healthy participants.

\subsection{Motion}

The processing of motion is assumed to be particularly well-preserved in blindsight patients. As noted by Azzopardi and Cowey (2001), "moving targets may be so salient that, in carefully controlled conditions, it can be difficult to discern whether the patients are actually 'blind' to them" (p. 30). Thus, motion processing is assumed to be a particularly strong visual capacity, possibly reflecting the fact that motion is processed by the pathways that project fast-acting magnocellular neurons directly to cortical area MT+/V5 or the parietal cortex (Ajina, Pestilli, et al., 2015a). This makes motion processing a very interesting feature to study in TMS paradigms.

Koivisto, Mäntylä, and Silvanto (2010) asked participants to report the direction of motion (left/right) and conscious perception of motion direction of random-dot displays. The conscious perception of motion direction was impaired when TMS was applied to the early visual cortex at an early $(20 \mathrm{~ms})$ or late $(60 \mathrm{~ms})$ delay after motion offset. Because TMS stimulation of MT+/V5 impaired motion discrimination and subjective perception at an intermediate (40 ms) TMS delay, the data support the idea that motion perception relies on the initial feedforward flow of activation to MT+/V5 through the V1. When the participants reported not seeing the direction of the motion, the performance on the forced-choice direction-task was above the level of chance (mean accuracy about $65 \%$ ). This unconscious discrimination of motion direction was selectively impaired when TMS was applied to V1 at the later TMS delay, suggesting that the discrimination of unconscious 
motion direction may rely on feedback to V1 (again, this is at odds with findings in blindsight patients).

In the study by Koivisto et al. (2010), visual suppression by TMS was not complete, but only subjective perception of the task-relevant visual feature (motion direction) was suppressed. Hence, as already noted, it is likely that the reported "unconscious" visual perception was more likely just degraded conscious vision. Hurme et al. (2019) used the RTE to examine whether TMSinduced blindsight can be observed with moving stimuli whose visibility was completely suppressed with V1 TMS. As shown in Figure 4C, when the visibility of the whole stimulus was suppressed with TMS (four SOAs: 45-105 ms), no unconscious RTE was observed. In contrast, robust unconscious RTE was observed when visual (metacontrast) masking was used (i.e., when the V1 activity was not interfered with TMS).

We conclude that there is currently no evidence for type-1 TMS-induced blindsight of visual motion.

\subsection{Affective information}

Jolij and Lamme (2005) used a paradigm where the participants had to indicate the emotion (happy vs. sad) and location (left vs. right) of an emotional face icon presented together with three neutral stimuli. The results showed that at $110 \mathrm{~ms}$ SOA, the participants could report the emotion of the stimulus (accuracy at around 66\%), even though they could not report its location. A similar effect was not observed at the $130 \mathrm{~ms}$ SOA. This result is not a strong demonstration of type-1 TMSinduced affective blindsight because the participants were not unconscious of the whole stimulus but were merely not conscious of the facial expression(s). Moreover, because the effect was only observed during specific SOA, it is inconsistent with the idea that unconscious affective processing completely bypasses V1. Finally, the results revealed complex learning effects and dependencies on the duration of the visual stimulation.

Filmer and Monsell (2013) showed that early visual cortical TMS selectively disrupted the sensitivity to perceive neutral body postures without influencing the perception of emotive body postures. This is consistent with the idea that affective or threatening information may have processing priority and work through other pathways than the geniculo-striate pathway. Yet, because in the study conscious visibility of the (relatively large) body stimuli was not completely suppressed, this finding does not count as an instance of TMS-induced blindsight.

In conclusion, it is too early to make conclusions about affective TMS-induced blindsight based on these studies.

\subsection{Studies employing masked priming or low-contrast stimuli}

Here, we discuss studies that cannot be unequivocally categorized as TMS-induced blindsight because (in addition to TMS) the visual stimulus was masked with another visual stimulus, or was low-contrast to begin with. This means that it is difficult to ascertain if TMS pulses have actually interfered with the visual processing in the V1 because stimuli are frequently unconscious simply because of weak stimulus intensity (or masking). These studies can still provide interesting information about the contribution of the early visual cortex to unconscious and conscious visual processing and, as discussed below, are generally consistent with the studies reviewed above.

Koivisto et al. (2012) showed that unconscious response priming by arrow-shaped stimuli depends on the early visual cortex, supporting the conclusion that shape cannot be unconsciously processed without the geniculo-striate projection (see also, Sack et al., 2009; Koivisto et al., 2014). Using an unconscious shape priming paradigm, Persuh and Ro (2013) showed that at 45 ms TMSSOA, visually masked prime stimuli that were unconscious could still produce a priming effect. 
Although the use of a binary visibility rating means that the performance may not have been strictly unconscious, the results suggest that early visual cortex may contribute to blindsight-like behavior at specific time windows.

Allen, Sumner, and Chambers (2014) asked participants to report the direction of an arrow stimulus, in addition to reporting what they saw. In this study, the intensity of the stimuli was calibrated to a level that resulted in conscious perception of the stimulus in $50 \%$ of the trials without TMS. Because the task was to report the direction of an arrow, the task was similar to orientation/ shape recognition. Conscious detection of the arrow stimulus was suppressed by paired TMS pulses delivered at 90 and $130 \mathrm{~ms}$ after visual stimulus. Because TMS did not reduce the frequency of correct arrow recognition reports during the unconscious trials, the authors concluded that TMSinduced blindsight was observed. However, a more likely explanation is that the TMS pulses were not effectively interfering with processing in the early visual cortex: the majority of stimuli (about $50 \%$ ) were unconscious because of the low intensity of the stimuli, and the TMS pulses increased the suppression rates by only about $10 \%$. Similar design was employed by Allen et al. (2020) with the exception that TMS pulses were applied to the early visual cortex in two varied time-points (at $110 \mathrm{~ms}$ SOA, and an additional pulse before or after). The results showed that TMS suppressed conscious and unconscious perception to similar degree, revealing no blindsight-like dissociation.

Railo et al. (2012) showed that TMS to the V1 decreases unconscious color priming. Even though the unconscious color priming effect was not completely eliminated, the results show that TMS pulses interfered with both the unconscious and conscious processing of color, suggesting that the two cannot be dissociated. Similarly, Koivisto et al. (2014) observed that early visual cortex TMS interfered with both conscious and unconscious color and shape discrimination.

\section{Discussion}

\subsection{Main conclusions}

The TMS studies indicate that when the task is to roughly localize or merely detect the presence of a stimulus, there is evidence of type-1 TMS-induced blindsight, but this effect may be restricted to situations where the early, feedforward stimulus-driven activity in the V1 is not interfered with (Hurme et al., 2017). There is no evidence for type-1 TMS-induced blindsight of orientation or chromatic information when conscious perception is measured using a strict procedure. TMS studies have, however, revealed a weaker form of dissociation between subjective visual experiences and visually guided behavior: when participants have reported that they do not consciously see the task-relevant feature (e.g., line orientation or color), but may see other features of the stimulus, they can still use the task-relevant feature to guide their behavior. Only a few studies have examined TMS-induced blindsight of motion or affective information, and these studies have failed to provide convincing evidence for such an effect (at least in a type-1 sense).

The lack of strong evidence for type-1 TMS-induced blindsight suggests that geniculostriate projection causally mediates both unconscious and conscious vision in neurologically healthy individuals and that visual pathways that bypass the V1 cannot alone support visually guided behavior in neurologically healthy individuals. As noted above, a possible exception to this is unconscious registration of stimulus presence or location. Altogether this suggests that type-1 blindsight, as possibly observed in patients, does not straightforwardly generalize to neurologically healthy participants. 


\subsection{Limitations of the TMS studies}

TMS studies have used small stimuli (often $<1^{\circ}$; Table 1 ) to effectively suppress conscious vision, but studies on patients have typically used large, high-intensity stimuli. It is possible that the pathways that mediate blindsight-like behavior require large and high contrast stimuli to be sufficiently activated (e.g., the LGN to V5/MT+ pathway; Ajina \& Bridge, 2018, 2019; Ajina, Pestilli, et al., 2015a). SC neurons are activated by even very small and brief duration stimuli (Cynader \& Berman, 1972; Schiller et al., 1974; Wurtz et al., 1980), and blindsight in patients does not seem to be limited to large stimuli. Savina and Guitton (2018) showed that small $\left(0.5^{\circ}\right)$ stimuli presented in the blind visual field influenced saccades towards the field with hemianopia in two hemidecorticate patients. The pattern of visuo-motor influence, as well as the fact that this was observed in hemidecorticate patients, suggests that the effect was mediated by the SC. Similarly, monkeys with V1 lesions display blindsight-like behavior in response to small stimuli (Mohler \& Wurtz, 1977). These observations mean that at least the possible unconscious capacity of blindsight patients and monkeys to process small stimuli unconsciously does not generalize to neurologically healthy individuals.

Even if blindsight of small stimuli may not generalize to neurologically healthy participants, one could argue that TMS studies would observe a type-1 blindsight, could they use sufficiently large stimuli (to e.g., sufficiently activate the LGN to V5/MT+ pathway). However, recent psychophysical studies (without TMS) of the relationship between subliminal perception and conscious experience challenge this claim. Peters and Lau (2015) observed (using a "criterion-free" psychophysical paradigm) that when participants failed to consciously evaluate a stimulus, they also performed at chance-level in the objective orientation discrimination task (the stimuli in this task subtended $111^{\circ}$ ). Railo et al. (2020) observed that above-chance unconscious location discrimination accuracy (unconscious here means the lowest alternative on a four-step scale) correlated with participants' criterion level and their sensitivity to consciously detect the stimuli (this study used $6.5^{\circ}$ stimuli). These results are at odds with the claim of type-1 blindsight that visual pathways that function outside conscious perception guide objective visual discrimination.

In addition to stimulus size and intensity, the content of the stimuli could also matter. From an evolutionary perspective, affective stimuli (e.g., fearful faces or threatening animals, (Le et al., 2013; Méndez-Bértolo et al., 2016)) could be needed to reveal blindsight in neurologically healthy individuals (Tamietto \& De Gelder, 2010). However, other evidence suggests that affective information cannot be unconsciously processed by humans, even when visual cortical activity is not interfered with TMS (Lähteenmäki, Hyönä, Koivisto, \& Nummenmaa, 2015; Rajananda, Zhu, \& Peters, 2020). Similarly, although evolutionarily relevant threatening animal stimuli may elicit prioritized processing, this effect seems to rely on conscious perception (Grassini, Holm, Railo, \& Koivisto, 2016). Although we argue that the ability of humans to guide their behavior based on unconscious perceptual information is very limited, we do not wish to imply that no type of unconscious perception exists. For instance, many of the TMS studies reviewed above are based on testing how unconscious perception is modulated by TMS to V1 (e.g. unconscious RTE; (Hurme et al., 2017, 2019)).

The aim of the TMS-induced blindsight studies has been to conceptually replicate findings on patients, but it is important to keep in mind that TMS pulses affect neural processing very differently than lesions. Whereas lesions can effectively eliminate processing in the affected area, the effect of TMS pulses may be best characterized as adding noise to the system (Koivisto et al., 2017; Rahnev et al., 2012; Ruzzoli et al., 2010; Schwarzkopf et al., 2011). It could be argued that this noise not only interferes with the processing in the stimulated area, but also affects the functioning of the processes that would mediate the unconscious visual capacity. For example, 
possibly because of the strong TMS-induced activity in the early visual cortex, activity in smaller extrageniculate or geniculate-extrastriate (e.g. LGN to $\mathrm{V} 5 / \mathrm{MT}+$ ) pathways may not be strong enough to drive cortical neurons in extrastriate visual areas to enable blindsight-like behavior.

Electrophysiological data on how TMS pulses produce the suppression of conscious vision are currently very limited. In humans, one study observed that single occipital TMS pulses inhibit visually evoked activity (Railo et al., 2015), whereas another study showed that TMS pulses may enhance specific visual-evoked potentials (Reichenbach et al., 2011). The reasoning that TMS pulses "interrupt" processing in the stimulated cortical area at the specific time point of stimulation may be incorrect, and what may matter is how TMS- and visual-evoked activation overlap with each other (Reichenbach et al., 2011). In general, TMS pulses produce complex responses in the brain (Li et al., 2017; Siebner et al., 2009), and their effects depend on the state of the cortex (Silvanto \& Pascual-Leone, 2008).

Although a subset of the TMS-induced blindsight studies have targeted the pulses to V1 based on anatomical images or retinotopic mapping (see, Table 1), no study has yet targeted stimulation predominantly at the V1 and not the nearby visual areas V2 and V3. If a blindsight-like capacity is mediated by geniculo-extrastriate pathways (e.g., LGN to the V2), then it is possible that TMS-induced blindsight can only be observed when stimulation is targeted predominantly at the V1 (though blindsight in patients can be observed even when lesions extend to extrastriate cortex (e.g. Baseler et al., 1999)). Another way to approach the differences between visual cortical areas would be to attempt to suppress conscious vision by aiming to target, for example, the V3, without stimulating the V1. Although this type of study would not be comparable to blindsight patients (who have, by definition, a V1 lesion), it could test whether the V1 specifically is necessary for unconscious vision: If, for instance, V3 stimulation suppresses conscious vision while retaining unconscious, blindsight-like behavior, the result would suggest that V1 is necessary for unconscious processing in neurologically healthy individuals.

Because blindsight is only observed in a subset of patients with visual cortical lesions and because different patients reveal different types of blindsight, it is also worth asking how much individual variation exists in TMS-induced blindsight. Perhaps the aim of finding group-level effects is misguided, and we should instead examine if a subset of individuals reveals consistent TMS-induced blindsight effects.

\subsection{Implications for blindsight}

The present results are generally at odd with the view that unconscious blindsight-like capacity is present in neurologically healthy individuals. This suggests that blindsight may reflect, at least in some individuals, reorganization of brain connectivity such as changes to white matter pathways, synaptic rearrangement, or "network level" changes due to the missing input from V1. Some cortically blind patients who have blindsight show anatomical connections that are not observed in patients without blindsight, or neurologically healthy controls (Bridge et al., 2008; Leh, JohansenBerg, \& Ptito, 2006; Tamietto et al., 2012). There is also evidence for altered functional connectivity in blindsight (Silvanto et al., 2009). Furthermore, pathways that exist in neurologically healthy brains may acquire a different functional role in blindsight after the visual cortical lesion. Evidence for this is provided by the finding that responses in V5/MT + in blindsight patients resembles that seen in V1 of neurologically healthy individual (Ajina, Kennard, et al., 2015; Ajina, Rees, et al., 2015). In sum, the presence of a lesion in V1 and subsequent neural reorganization are likely to change the way visually evoked activity spreads in the brain in patients with visual cortical lesions. 
To what extent is type-1 blindsight enabled by the lesion and subsequent neuroplastic changes? Lesions acquired during childhood are likely to lead to more significant changes in connectivity (Warner et al., 2015), and in these patients there is also significant sparing of vision despite the lesion to early visual cortex (Guzzetta et al., 2010; Moore, Rodman, Repp, Gross, \& Mezrich, 1996; Mundinano et al., 2019). In many patients with occipital stroke, some visual contrast sensitivity may be retained during the subacute period (i.e. after the acute period, when e.g. swelling and inflammation have resolved) (Saionz, Tadin, Melnick, \& Huxlin, 2020). This suggests that early training of cortical blindness may allow to preserve conscious vision.

Vision restitution therapies can lead to significant improvements deep in the affected visual field locations even in chronic cortically blind adult patients (Chokron et al., 2008; Das et al., 2014; Melnick et al., 2016; Raninen, Vanni, Hyvärinen, \& Näsänen, 2007; Sahraie et al., 2006). There is some evidence that training may enable type-1 blindsight in some participants (Sahraie et al., 2006; Sahraie, Trevethan, Macleod, Weiskrantz, \& Hunt, 2013). However, often training results in increased awareness of the stimuli (Chokron et al., 2008; Sahraie et al., 2006, 2013). This suggests that the plasticity that possibly enables blindsight may also allow the patients to introspect the stimuli presented in the scotoma. That is, perhaps what has been traditionally interpreted as an unconscious capacity that reveals a dissociation of the functional and experiential aspects of vision in fact reflects partial recovery conscious perception: the visual system adapts to the lesion, enabling not only residual visual function, but also experience. The subjective experience enabled by neural adaptation could manifest as type- 2 blindsight where the patient claims not "seeing", but having "feelings" about what might be the correct answer. Yet, type- 2 blindsight resembles vision in the sense that the experiences that the patients report are caused by the visual stimuli (i.e., the type-2 feeling are "about" the visual stimulus). This could reflect some initial stage of the recovery of vision. In sum, V1 lesions may not completely eliminate conscious vision (Ffytche \& Zeki, 2011; Mazzi et al., 2019; Riddoch, 1917), but by relying on insensitive measures of conscious vision, previous research may have erroneously concluded that blindsight reveals unconscious perception (Campion et al., 1983; Overgaard et al. 2008; Mazzi et al. 2016; for a review, see Phillips 2020).

\subsection{Summary}

We have shown that there is currently little evidence for strictly unconscious brain stimulation induced blindsight in neurologically healthy observers. This means that there is discrepancy between visual behavior observed in some patients with cortical lesions, and healthy individuals when lesions are "mimicked" with non-invasive brain stimulation. This difference could be explained by various methodological factors (e.g., small size of stimuli used in brain stimulation studies). However, the results also suggest a possible reinterpretation of blindsight: What has been taken as evidence for visually guided behavior based on pathways that function outside consciousness may be a form of partially recovered or preserved conscious vision.

\section{Acknowledgements}

We thank Holly Bridge, Mika Koivisto and two anonymous reviewers for their helpful comments.

\section{Funding statement}

H.R. was funded by the Academy of Finland (grant \#308533). 


\section{References}

Ajina, S., \& Bridge, H. (2018). Blindsight relies on a functional connection between hMT+ and the lateral geniculate nucleus, not the pulvinar. PLoS Biology. https://doi.org/10.1371/ journal.pbio. 2005769

Ajina, S., Kennard, C., Rees, G., \& Bridge, H. (2015). Motion area V5/MT+ response to global motion in the absence of V1 resembles early visual cortex. Brain. https://doi.org/10.1093/ brain/awu328

Ajina, S., Pestilli, F., Rokem, A., Kennard, C., \& Bridge, H. (2015a). Human blindsight is mediated by an intact geniculo-extrastriate pathway. ELife. https://doi.org/10.7554/eLife.08935

Ajina, S., Pestilli, F., Rokem, A., Kennard, C., \& Bridge, H. (2015b). Human blindsight is mediated by an intact geniculo-extrastriate pathway. ELife. https://doi.org/10.7554/elife.08935

Ajina, S., Rees, G., Kennard, C., \& Bridge, H. (2015). Abnormal contrast responses in the extrastriate cortex of blindsight patients. Journal of Neuroscience. https://doi.org/10.1523/ JNEUROSCI.3075-14.2015

Allen, C. P. G., Sumner, P., \& Chambers, C. D. (2014). The timing and neuroanatomy of conscious vision as revealed by TMS-induced blindsight. Journal of Cognitive Neuroscience. https:// doi.org/10.1162/jocn_a_00557

Allen, C., Viola, T., Irvine, E., Sedgmond, J., Castle, H., Gray, R., \& Chambers, C. D. (2020). Causal manipulation of feed-forward and recurrent processing differentially affects measures of consciousness. Neuroscience of Consciousness. https://doi.org/10.1093/nc/niaa015

Amassian, V. E., Cracco, R. Q., Maccabee, P. J., Cracco, J. B., Rudell, A., \& Eberle, L. (1989). Suppression of visual perception by magnetic coil stimulation of human occipital cortex. Electroencephalography and Clinical Neurophysiology/Evoked Potentials. https://doi.org/ 10.1016/0168-5597(89)90036-1

Azzopardi, P., \& Cowey, A. (1997). Is blindsight like normal, near-threshold vision? Proceedings of the National Academy of Sciences of the United States of America. https://doi.org/10.1073/ pnas.94.25.14190

Azzopardi, P., \& Cowey, A. (2001). Motion discrimination in cortically blind patients. Brain. https://doi.org/10.1093/brain/124.1.30

Baldwin, M. K. L., Balaram, P., \& Kaas, J. H. (2017). The evolution and functions of nuclei of the visual pulvinar in primates. Journal of Comparative Neurology. https://doi.org/10.1002/ cne. 24272

Baseler, H. A., Morland, A. B., \& Wandell, B. A. (1999). Topographic organization of human visual areas in the absence of input from primary cortex. Journal of Neuroscience. https://doi.org/ 10.1523/jneurosci.19-07-02619.1999

Basso, M. A., \& May, P. J. (2017). Circuits for Action and Cognition: A View from the Superior Colliculus. Annual Review of Vision Science. https://doi.org/10.1146/annurevvision-102016-061234

Benevento, L. A., \& Yoshida, K. (1981). The afferent and efferent organization of the lateral geniculo-prestriate pathways in the macaque monkey. Journal of Comparative Neurology. https://doi.org/10.1002/cne.902030309

Blythe, I. M., Bromley, J. M., Kennard, C., \& Ruddock, K. H. (1986). Visual discrimination of target displacement remains after damage to the striate cortex in humans. Nature. https:// doi.org/10.1038/320619a0

Bola, M., Gall, C., \& Sabel, B. A. (2013). "Sightblind": Perceptual deficits in the "intact" visual field. Frontiers in Neurology. https://doi.org/10.3389/fneur.2013.00080

Boyer, J. L., Harrison, S., \& Ro, T. (2005). Unconscious processing of orientation and color without 
primary visual cortex. Proceedings of the National Academy of Sciences. https://doi.org/ 10.1073/pnas.0505332102

Bridge, H., Hicks, S. L., Xie, J., Okell, T. W., Mannan, S., Alexander, I., ... Kennard, C. (2010). Visual activation of extra-striate cortex in the absence of V1 activation. Neuropsychologia. https://doi.org/10.1016/j.neuropsychologia.2010.10.022

Bridge, H., Thomas, O., Jbabdi, S., \& Cowey, A. (2008). Changes in connectivity after visual cortical brain damage underlie altered visual function. Brain. https://doi.org/10.1093/brain/ awn063

Bullier, J., \& Kennedy, H. (1983). Projection of the lateral geniculate nucleus onto cortical area V2 in the macaque monkey. Experimental Brain Research. https://doi.org/10.1007/BF00239409

Buzsaki, G. (2019). The Brain from Inside Out. Oxford University Press.

Campion, J., Latto, R., \& Smith, Y. M. (1983). Is blindsight an effect of scattered light, spared cortex, and near-threshold vision? Behavioral and Brain Sciences. https://doi.org/10.1017/ S0140525X00016861

Celeghin, A., Bagnis, A., Diano, M., Méndez, C. A., Costa, T., \& Tamietto, M. (2019). Functional neuroanatomy of blindsight revealed by activation likelihood estimation meta-analysis. Neuropsychologia. https://doi.org/10.1016/j.neuropsychologia.2018.06.007

Chokron, S., Perez, C., Obadia, M., Gaudry, I., Laloum, L., \& Gout, O. (2008). From blindsight to sight: Cognitive rehabilitation of visual field defects. Restorative Neurology and Neuroscience.

Christensen, M. S., Kristiansen, L., Rowe, J. B., \& Nielsen, J. B. (2008). Action-blindsight in healthy subjects after transcranial magnetic stimulation. Proceedings of the National Academy of Sciences. https://doi.org/10.1073/pnas.0705858105

Cowey, A., Stoerig, P., \& Bannister, M. (1994). Retinal ganglion cells labelled from the pulvinar nucleus in macaque monkeys. Neuroscience. https://doi.org/10.1016/0306-4522(94)90445-6

Cowey, Alan. (2010). The blindsight saga. Experimental Brain Research. https://doi.org/10.1007/ s00221-009-1914-2

Crook, J. D., Peterson, B. B., Packer, O. S., Robinson, F. R., Troy, J. B., \& Dacey, D. M. (2008). Ycell receptive field and collicular projection of parasol ganglion cells in macaque monkey retina. Journal of Neuroscience. https://doi.org/10.1523/JNEUROSCI.2982-08.2008

Cynader, M., \& Berman, N. (1972). Receptive-field organization of monkey superior colliculus. Journal of Neurophysiology. https://doi.org/10.1152/jn.1972.35.2.187

Danckert, J., \& Rossetti, Y. (2005). Blindsight in action: What can the different sub-types of blindsight tell us about the control of visually guided actions? Neuroscience and Biobehavioral Reviews. https://doi.org/10.1016/j.neubiorev.2005.02.001

Danckert, J., Tamietto, M., \& Rossetti, Y. (2019). Definition: Blindsight. Cortex. https://doi.org/ 10.1016/j.cortex.2019.01.027

Das, A., Tadin, D., \& Huxlin, K. R. (2014). Beyond blindsight: Properties of visual relearning in cortically blind fields. Journal of Neuroscience. https://doi.org/10.1523/ JNEUROSCI.1076-14.2014

de Gelder, Beatrice, Tamietto, M., van Boxtel, G., Goebel, R., Sahraie, A., van den Stock, J., ... Pegna, A. (2008). Intact navigation skills after bilateral loss of striate cortex. Current Biology. https://doi.org/10.1016/j.cub.2008.11.002

De Gelder, Béatrice, Vroomen, J., Pourtois, G., \& Weiskrantz, L. (1999). Non-conscious recognition of affect in the absence of striate cortex. NeuroReport. https://doi.org/ 10.1097/00001756-199912160-00007

Douglas, R. J., \& Martin, K. A. C. (2007). Mapping the matrix: the ways of neocortex. Neuron. https://doi.org/10.1016/j.neuron.2007.10.017

Ffytche, D. H., \& Zeki, S. (2011). The primary visual cortex, and feedback to it, are not necessary 
for conscious vision. Brain. https://doi.org/10.1093/brain/awq305

Filmer, H. L., \& Monsell, S. (2013). TMS to V1 spares discrimination of emotive relative to neutral body postures. Neuropsychologia. https://doi.org/10.1016/j.neuropsychologia.2013.09.029

Foxe, J. J., \& Simpson, G. V. (2002). Flow of activation from V1 to frontal cortex in humans: A framework for defining "early" visual processing. Experimental Brain Research. https:// doi.org/10.1007/s00221-001-0906-7

Gattass, R., Galkin, T. W., Desimone, R., \& Ungerleider, L. G. (2014). Subcortical connections of area V4 in the macaque. Journal of Comparative Neurology. https://doi.org/10.1002/cne.23513

Ghodrati, M., Khaligh-Razavi, S. M., \& Lehky, S. R. (2017). Towards building a more complex view of the lateral geniculate nucleus: Recent advances in understanding its role. Progress in Neurobiology. https://doi.org/10.1016/j.pneurobio.2017.06.002

Goebel, R., Muckli, L., Zanella, F. E., Singer, W., \& Stoerig, P. (2001). Sustained extrastriate cortical activation without visual awareness revealed by fMRI studies of hemianopic patients. In Vision Research. https://doi.org/10.1016/S0042-6989(01)00069-4

Grassini, S., Holm, S. K., Railo, H., \& Koivisto, M. (2016). Who is afraid of the invisible snake? Subjective visual awareness modulates posterior brain activity for evolutionarily threatening stimuli. Biological Psychology. https://doi.org/10.1016/j.biopsycho.2016.10.007

Guzzetta, A., D'acunto, G., Rose, S., Tinelli, F., Boyd, R., \& Cioni, G. (2010). Plasticity of the visual system after early brain damage. Developmental Medicine and Child Neurology. https:// doi.org/10.1111/j.1469-8749.2010.03710.x

Henriksson, L., Karvonen, J., Salminen-Vaparanta, N., Railo, H., \& Vanni, S. (2012). Retinotopic maps, spatial tuning, and locations of human visual areas in surface coordinates characterized with multifocal and blocked fMRI designs. PLoS ONE. https://doi.org/10.1371/ journal.pone.0036859

Heron, Z. (2000). Brain Story - The Final Mystery. BBC.

Hinds, O. P., Rajendran, N., Polimeni, J. R., Augustinack, J. C., Wiggins, G., Wald, L. L., ... Fischl, B. (2008). Accurate prediction of V1 location from cortical folds in a surface coordinate system. NeuroImage. https://doi.org/10.1016/j.neuroimage.2007.10.033

Humphrey, N. (1972). Seeing and nothingness. New Scientist, 30.

Humphrey, N. K., \& Weiskrantz, L. (1967). Vision in monkeys after removal of the striate cortex. Nature. https://doi.org/10.1038/215595a0

Hurme, M., Koivisto, M., Henriksson, L., \& Railo, H. (2020). Neuronavigated TMS of early visual cortex eliminates unconscious processing of chromatic stimuli. Neuropsychologia. https:// doi.org/10.1016/j.neuropsychologia.2019.107266

Hurme, M., Koivisto, M., Revonsuo, A., \& Railo, H. (2017). Early processing in primary visual cortex is necessary for conscious and unconscious vision while late processing is necessary only for conscious vision in neurologically healthy humans. NeuroImage. https://doi.org/ 10.1016/j.neuroimage.2017.02.060

Hurme, M., Koivisto, M., Revonsuo, A., \& Railo, H. (2019). V1 activity during feedforward and early feedback processing is necessary for both conscious and unconscious motion perception. NeuroImage. https://doi.org/10.1016/j.neuroimage.2018.10.058

Jayakumar, J., Roy, S., Dreher, B., Martin, P. R., \& Vidyasagar, T. R. (2013). Multiple pathways carry signals from short-wavelength-sensitive ('blue') cones to the middle temporal area of the macaque. Journal of Physiology. https://doi.org/10.1113/jphysiol.2012.241117

Jolij, J., \& Lamme, V. A. F. (2005). Repression of unconscious information by conscious processing: Evidence from affective blindsight induced by transcranial magnetic stimulation. Proceedings of the National Academy of Sciences of the United States of America. https:// doi.org/10.1073/pnas.0500834102 
King, J. R., \& Dehaene, S. (2014). A model of subjective report and objective discrimination as categorical decisions in a vast representational space. Philosophical Transactions of the Royal Society B: Biological Sciences. https://doi.org/10.1098/rstb.2013.0204

Kinoshita, M., Kato, R., Isa, K., Kobayashi, K., Kobayashi, K., Onoe, H., \& Isa, T. (2019). Dissecting the circuit for blindsight to reveal the critical role of pulvinar and superior colliculus. Nature Communications. https://doi.org/10.1038/s41467-018-08058-0

Ko, Y., \& Lau, H. (2012). A detection theoretic explanation of blindsight suggests a link between conscious perception and metacognition. Philosophical Transactions of the Royal Society B: Biological Sciences. https://doi.org/10.1098/rstb.2011.0380

Koenig, L., \& Ro, T. (2019). Dissociations of conscious and unconscious perception in TMSinduced blindsight. Neuropsychologia. https://doi.org/10.1016/j.neuropsychologia.2018.03.028

Koivisto, M., Harjuniemi, I., Railo, H., Salminen-Vaparanta, N., \& Revonsuo, A. (2017). Transcranial magnetic stimulation of early visual cortex suppresses conscious representations in a dichotomous manner without gradually decreasing their precision. NeuroImage. https:// doi.org/10.1016/j.neuroimage.2017.07.011

Koivisto, M., Henriksson, L., Revonsuo, A., \& Railo, H. (2012). Unconscious response priming by shape depends on geniculostriate visual projection. European Journal of Neuroscience. https:// doi.org/10.1111/j.1460-9568.2011.07973.x

Koivisto, M., Lähteenmäki, M., Kaasinen, V., Parkkola, R., \& Railo, H. (2014). Overlapping activity periods in early visual cortex and posterior intraparietal area in conscious visual shape perception: A TMS study. NeuroImage. https://doi.org/10.1016/j.neuroimage.2013.09.051

Koivisto, M., Mäntylä, T., \& Silvanto, J. (2010). The role of early visual cortex (V1/V2) in conscious and unconscious visual perception. NeuroImage. https://oi.org/10.1016/ j.neuroimage.2010.02.042

Koivisto, M., Railo, H., \& Salminen-Vaparanta, N. (2011). Transcranial magnetic stimulation of early visual cortex interferes with subjective visual awareness and objective forced-choice performance. Consciousness and Cognition. https://doi.org/10.1016/j.concog.2010.09.001

Lähteenmäki, M., Hyönä, J., Koivisto, M., \& Nummenmaa, L. (2015). Affective processing requires awareness. Journal of Experimental Psychology: General. https://doi.org/10.1037/ xge 0000040

Lamme, V. A. F., \& Roelfsema, P. R. (2000). The distinct modes of vision offered by feedforward and recurrent processing. Trends in Neurosciences. https://doi.org/10.1016/ S0166-2236(00)01657-X

Le, Q. Van, Isbell, L. A., Matsumoto, J., Nguyen, M., Hori, E., Maior, R. S., ... Nishijo, H. (2013). Pulvinar neurons reveal neurobiological evidence of past selection for rapid detection of snakes. Proceedings of the National Academy of Sciences of the United States of America. https://doi.org/10.1073/pnas.1312648110

LeDoux, J. (2012). Rethinking the Emotional Brain. Neuron. https://doi.org/10.1016/ j.neuron.2012.02.004

Leh, S. E., Johansen-Berg, H., \& Ptito, A. (2006). Unconscious vision: New insights into the neuronal correlate of blindsight using diffusion tractography. Brain. https://doi.org/10.1093/ brain/awl111

Leh, S. E., Mullen, K. T., \& Ptito, A. (2006). Absence of S-cone input in human blindsight following hemispherectomy. European Journal of Neuroscience. https://doi.org/10.1111/ j.1460-9568.2006.05178.x

Li, B., Virtanen, J. P., Oeltermann, A., Schwarz, C., Giese, M. A., Ziemann, U., \& Benali, A. (2017). Lifting the veil on the dynamics of neuronal activities evoked by transcranial magnetic stimulation. ELife. https://doi.org/10.7554/eLife.e30552 
Lin, C. -S, \& Kaas, J. H. (1979). The inferior pulvinar complex in owl monkeys: Architectonic subdivisions and patterns of input from the superior colliculus and subdivisions of visual cortex. Journal of Comparative Neurology. https://doi.org/10.1002/cne.901870403

Lloyd, D. A., Abrahamyan, A., \& Harris, J. A. (2013). Brain-stimulation induced blindsight: Unconscious vision or response bias? PLOS ONE. https://doi.org/10.1371/ journal.pone.0082828

Lyon, D. C., Nassi, J. J., \& Callaway, E. M. (2010). A Disynaptic Relay from Superior Colliculus to Dorsal Stream Visual Cortex in Macaque Monkey. Neuron. https:/doi.org/10.1016/ j.neuron.2010.01.003

Lyon, D. C., \& Rabideau, C. (2012). Lack of robust LGN label following transneuronal rabies virus injections into macaque area V4. Journal of Comparative Neurology. https://doi.org/10.1002/ cne. 23050

Marcel, A. J. (1998). Blindsight and shape perception: Deficit of visual consciousness or of visual function? Brain. https://doi.org/10.1093/brain/121.8.1565

Markov, N. T., Misery, P., Falchier, A., Lamy, C., Vezoli, J., Quilodran, R., ... Knoblauch, K. (2011). Weight consistency specifies regularities of macaque cortical networks. Cerebral Cortex. https://doi.org/10.1093/cercor/bhq201

Marzi, C. A., Tassinari, G., Aglioti, S., \& Lutzemberger, L. (1986). Spatial summation across the vertical meridian in hemianopics: A test of blindsight. Neuropsychologia. https://doi.org/ 10.1016/0028-3932(86)90074-6

Mazzi, C., Bagattini, C., \& Savazzi, S. (2016). Blind-sight vs. degraded-sight: Different measures tell a different story. Frontiers in Psychology. https://doi.org/10.3389/fpsyg.2016.00901

Mazzi, C., Savazzi, S., \& Silvanto, J. (2019). On the "blindness" of blindsight: What is the evidence for phenomenal awareness in the absence of primary visual cortex (V1)? Neuropsychologia. https://doi.org/10.1016/j.neuropsychologia.2017.10.029

Melnick, M. D., Tadin, D., \& Huxlin, K. R. (2016). Relearning to See in Cortical Blindness. Neuroscientist. https://doi.org/10.1177/1073858415621035

Méndez-Bértolo, C., Moratti, S., Toledano, R., Lopez-Sosa, F., Martínez-Alvarez, R., Mah, Y. H., ... Strange, B. A. (2016). A fast pathway for fear in human amygdala. Nature Neuroscience. https://doi.org/10.1038/nn.4324

Mohler, C. W., \& Wurtz, R. H. (1977). Role of striate cortex and superior colliculus in visual guidance of saccadic eye movements in monkeys. Journal of Neurophysiology. https://doi.org/ 10.1152/jn.1977.40.1.74

Moore, T., Rodman, H. R., Repp, A. B., Gross, C. G., \& Mezrich, R. S. (1996). Greater residual vision in monkeys after striate cortex damage in infancy. Journal of Neurophysiology. https:// doi.org/10.1152/jn.1996.76.6.3928

Muckli, L., \& Petro, L. S. (2013). Network interactions: Non-geniculate input to V1. Current Opinion in Neurobiology. https://doi.org/10.1016/j.conb.2013.01.020

Mundinano, I. C., Chen, J., de Souza, M., Sarossy, M. G., Joanisse, M. F., Goodale, M. A., \& Bourne, J. A. (2019). More than blindsight: Case report of a child with extraordinary visual capacity following perinatal bilateral occipital lobe injury. Neuropsychologia. https://doi.org/ 10.1016/j.neuropsychologia.2017.11.017

Nakagawa, S., \& Tanaka, S. (1984). Retinal projections to the pulvinar nucleus of the macaque monkey: a re-investigation using autoradiography. Experimental Brain Research. https:// doi.org/10.1007/BF00231141

O’Brien, B. J., Abel, P. L., \& Olavarria, J. F. (2001). The retinal input to calbindin-D28k-defined subdivisions in macaque inferior pulvinar. Neuroscience Letters. https://doi.org/10.1016/ 
S0304-3940(01)02220-0

Öhman, A., \& Mineka, S. (2001). Fears, phobias, and preparedness: Toward an evolved module of fear and fear learning. Psychological Review. https://doi.org/10.1037/0033-295X.108.3.483

Overgaard, M. (2011). Visual experience and blindsight: A methodological review. Experimental Brain Research. https://doi.org/10.1007/s00221-011-2578-2

Overgaard, M., Fehl, K., Mouridsen, K., Bergholt, B., \& Cleeremans, A. (2008). Seeing without seeing? Degraded conscious vision in a blindsight patient. PLoS ONE. https://doi.org/10.1371/ journal.pone. 0003028

Overgaard, M., Rote, J., Mouridsen, K., \& Ramsøy, T. Z. (2006). Is conscious perception gradual or dichotomous? A comparison of report methodologies during a visual task. Consciousness and Cognition. https://doi.org/10.1016/j.concog.2006.04.002

Pavan, A., Alexander, I., Campana, G., \& Cowey, A. (2011). Detection of first- and second-order coherent motion in blindsight. Experimental Brain Research. https://doi.org/10.1007/ s00221-011-2828-3

Perenin, M. T. (1991). Discrimination of motion direction in perimetrically blind fields. NeuroReport. https://doi.org/10.1097/00001756-199107000-00011

Perry, V. H., \& Cowey, A. (1984). Retinal ganglion cells that project to the superior colliculus and pretectum in the macaque monkey. Neuroscience. https://doi.org/ 10.1016/0306-4522(84)90007-1

Persuh, M., \& Ro, T. (2013). Unconscious Priming Requires Early Visual Cortex at Specific Temporal Phases of Processing. Journal of Cognitive Neuroscience. https://doi.org/10.1162/ jocn_a_00423

Pessoa, L. (2014). Understanding brain networks and brain organization. https://doi.org/10.1016/ j.plrev.2014.03.005

Pessoa, L., \& Adolphs, R. (2010). Emotion processing and the amygdala: From a "low road" to "many roads" of evaluating biological significance. Nature Reviews Neuroscience. https:// doi.org/10.1038/nrn2920

Peters, M. A. K., Fesi, J., Amendi, N., Knotts, J. D., Lau, H., \& Ro, T. (2017). Transcranial magnetic stimulation to visual cortex induces suboptimal introspection. Cortex. https://doi.org/ 10.1016/j.cortex.2017.05.017

Peters, M. A. K., \& Lau, H. (2015). Human observers have optimal introspective access to perceptual processes even for visually masked stimuli. ELife. https://doi.org/10.7554/ eLife.09651

Phillips, I. (2020). Blindsight Is Qualitatively Degraded Conscious Vision. Psychological Review. https://doi.org/10.1037/rev0000254

Pöppel, E., Held, R., \& Frost, D. (1973). Residual visual function after Brain Wounds involving the central visual pathways in Man. Nature, 243(5405), 295-296. https://doi.org/ $10.1038 / 243295 \mathrm{a} 0$

Rafal, R., Smith, J., Krantz, A., Cohen, C. B. (1990). Extrageniculate vision in hemianopic humans: saccade inhibition by signals in the blind field. Science, 250, 118-121.

Rahnev, D. A., Maniscalco, B., Luber, B., Lau, H., \& Lisanby, S. H. (2012). Direct injection of noise to the visual cortex decreases accuracy but increases decision confidence. Journal of Neurophysiology. https://doi.org/10.1152/jn.00985.2011

Railo, H., Piccin, R., Lukasik, K. (2020). Subliminal perception can be predicted from prestimulus activity. BioRxiv.

Railo, H., Andersson, E., Kaasinen, V., Laine, T., \& Koivisto, M. (2014). Unlike in clinical blindsight patients, unconscious processing of chromatic information depends on early visual cortex in healthy humans. Brain Stimulation. https://doi.org/10.1016/j.brs.2014.01.060 
Railo, H., \& Koivisto, M. (2012). Two means of suppressing visual awareness: A direct comparison of visual masking and transcranial magnetic stimulation. Cortex. https://doi.org/10.1016/ j.cortex.2010.12.001

Railo, H., Revonsuo, A., \& Koivisto, M. (2015). Behavioral and electrophysiological evidence for fast emergence of visual consciousness. Neuroscience of Consciousness. https://doi.org/ 10.1093/nc/niv004

Railo, H., Salminen-Vaparanta, N., Henriksson, L., Revonsuo, A., \& Koivisto, M. (2012). Unconscious and conscious processing of color rely on activity in early visual cortex: A TMS study. Journal of Cognitive Neuroscience. https://doi.org/10.1162/jocn_a_00172

Rajananda, S., Zhu, J., \& Peters, M. A. K. (2020). Normal observers show no evidence for blindsight in facial emotion perception. Neuroscience of Consciousness. https://doi.org/ $10.1093 / \mathrm{nc} / \mathrm{niaa} 023$

Ramsøy, T. Z., \& Overgaard, M. (2004). Introspection and subliminal perception. Phenomenology and the Cognitive Sciences. https://doi.org/10.1023/b:phen.0000041900.30172.e8

Raninen, A., Vanni, S., Hyvärinen, L., \& Näsänen, R. (2007). Temporal sensitivity in a hemianopic visual field can be improved by long-term training using flicker stimulation. Journal of Neurology, Neurosurgery and Psychiatry. https://doi.org/10.1136/jnnp.2006.099366

Reichenbach, A., Whittingstall, K., \& Thielscher, A. (2011). Effects of transcranial magnetic stimulation on visual evoked potentials in a visual suppression task. NeuroImage. https:// doi.org/10.1016/j.neuroimage.2010.08.047

Riddoch, G. (1917). Dissociation of visual perceptions due to occipital injuries, with especial reference to appreciation of movement. Brain. https://doi.org/10.1093/brain/40.1.15

Ro, T., Shelton, D., Lee, O. L., \& Chang, E. (2004). Extrageniculate mediation of unconscious vision in transcranial magnetic stimulation-induced blindsight. Proceedings of the National Academy of Sciences. https://doi.org/10.1073/pnas.0403061101

Ro, Tony. (2008). Unconscious vision in action. Neuropsychologia, 46, 379-383.

Rohatgi, A. (2015). WebPlotDigitizer.

Ruzzoli, M., Marzi, C. A., \& Miniussi, C. (2010). The neural mechanisms of the effects of transcranial magnetic stimulation on perception. Journal of Neurophysiology. https://doi.org/ 10.1152/jn.01096.2009

Sack, A. T., van der Mark, S., Schuhmann, T., Schwarzbach, J., \& Goebel, R. (2009). Symbolic action priming relies on intact neural transmission along the retino-geniculo-striate pathway. NeuroImage. https://doi.org/10.1016/j.neuroimage.2008.07.030

Sahraie, A., Trevethan, C. T., MacLeod, M. J., Murray, A. D., Olson, J. A., \& Weiskrantz, L. (2006). Increased sensitivity after repeated stimulation of residual spatial channels in blindsight. Proceedings of the National Academy of Sciences of the United States of America. https:// doi.org/10.1073/pnas.0607073103

Sahraie, A., Trevethan, C. T., Macleod, M. J., Weiskrantz, L., \& Hunt, A. R. (2013). The continuum of detection and awareness of visual stimuli within the blindfield: from blindsight to the sighted-sight. Investigative Ophthalmology \& Visual Science. https://doi.org/10.1167/ iovs.12-11231

Saionz, E. ., Tadin, D., Melnick, M. ., \& Huxlin, K. . (2020). Functional preservation and enhanced capacity for visual restoration in subacute occipital stroke. Brain, 128.

Salminen-Vaparanta, N., Noreika, V., Revonsuo, A., Koivisto, M., \& Vanni, S. (2012). Is selective primary visual cortex stimulation achievable with TMS? Human Brain Mapping. https:// doi.org/10.1002/hbm.21237

Sandberg, K., Timmermans, B., Overgaard, M., \& Cleeremans, A. (2010). Measuring consciousness: Is one measure better than the other? Consciousness and Cognition. https:// 
doi.org/10.1016/j.concog.2009.12.013

Sanders, M. D., Warrington, E. K., Marshall, J., \& Wieskrantz, L. (1974). "BLINDSIGHT": VISION IN A FIELD DEFECT. The Lancet. https://doi.org/10.1016/S0140-6736(74)92907-9

Saturnino, G. B., Puonti, O., Nielsen, J. D., Antonenko, D., Madsen, K. H., \& Thielscher, A. (2019). SimNIBS 2.1: A Comprehensive Pipeline for Individualized Electric Field Modelling for Transcranial Brain Stimulation. In Brain and Human Body Modeling. https://doi.org/ 10.1007/978-3-030-21293-3_1

Savina, O., \& Guitton, D. (2018). The primitive retino-tecto-reticular pathway is functional in hemidecorticate patients. Current Biology. https://doi.org/10.1016/j.cub.2018.09.006

Schiller, P. H., \& Malpeli, J. G. (1977). Properties and tectal projections of monkey retinal ganglion cells. Journal of Neurophysiology. https://doi.org/10.1152/jn.1977.40.2.428

Schiller, P. H., Stryker, M., Cynader, M., \& Berman, N. (1974). Response characteristics of single cells in the monkey superior colliculus following ablation or cooling of visual cortex. Journal of Neurophysiology. https://doi.org/10.1152/jn.1974.37.1.181

Schmid, M. C., Mrowka, S. W., Turchi, J., Saunders, R. C., Wilke, M., Peters, A. J., ... Leopold, D. A. (2010). Blindsight depends on the lateral geniculate nucleus. Nature. https://doi.org/ 10.1038/nature09179

Schwarzkopf, D. S., Silvanto, J., \& Rees, G. (2011). Stochastic resonance effects reveal the neural mechanisms of transcranial magnetic stimulation. Journal of Neuroscience. https://doi.org/ 10.1523/JNEUROSCI.4863-10.2011

Sherman, S. M., \& Guillery, R. W. (2002). The role of the thalamus in the flow of information to the cortex. In Philosophical Transactions of the Royal Society B: Biological Sciences. https:// doi.org/10.1098/rstb.2002.1161

Shipp, S. (2003). The functional logic of cortico-pulvinar connections. Philosophical Transactions of the Royal Society B: Biological Sciences. https://doi.org/10.1098/rstb.2002.1213

Siebner, H. R., Hartwigsen, G., Kassuba, T., \& Rothwell, J. C. (2009). How does transcranial magnetic stimulation modify neuronal activity in the brain? Implications for studies of cognition. Cortex. https://doi.org/10.1016/j.cortex.2009.02.007

Sillito, A. M., Cudeiro, J., \& Jones, H. E. (2006). Always returning: feedback and sensory processing in visual cortex and thalamus. Trends in Neurosciences. https://doi.org/10.1016/ j.tins.2006.05.001

Silvanto, J., \& Pascual-Leone, A. (2008). State-dependency of transcranial magnetic stimulation. Brain Topography. https://doi.org/10.1007/s10548-008-0067-0

Silvanto, J., Walsh, V., \& Cowey, A. (2009). Abnormal functional connectivity between ipsilesional V5/MT+ and contralesional striate cortex (V1) in blindsight. Experimental Brain Research. https://doi.org/10.1007/s00221-009-1712-x

Sincich, L. C., Park, K. F., Wohlgemuth, M. J., \& Horton, J. C. (2004). Bypassing V1: A direct geniculate input to area MT. Nature Neuroscience. https://doi.org/10.1038/nn1318

Stoerig, P. (1987). Chromaticity and achromaticity: Evidence for a functional differentiation in visual field defects. Brain. https://doi.org/10.1093/brain/110.4.869

Stoerig, P., \& Cowey, A. (1992). Wavelength discrimination in blindsight. Brain. https://doi.org/ 10.1093/brain/115.2.425

Stoerig, P., \& Cowey, A. (1997). Blindsight in man and monkey. Brain. https://doi.org/10.1093/ brain/120.3.535

Striemer, C. L., Whitwell, R. L., \& Goodale, M. A. (2019). Affective blindsight in the absence of input from face processing regions in occipital-temporal cortex. Neuropsychologia. https:// doi.org/10.1016/j.neuropsychologia.2017.11.014

Tamietto, M., Cauda, F., Corazzini, L. L., Savazzi, S., Marzi, C. A., Goebel, R., ... De Gelder, B. 
(2010). Collicular vision guides nonconscious behavior. Journal of Cognitive Neuroscience. https://doi.org/10.1162/jocn.2009.21225

Tamietto, M., \& De Gelder, B. (2010). Neural bases of the non-conscious perception of emotional signals. Nature Reviews Neuroscience. https://doi.org/10.1038/nrn2889

Tamietto, M., Pullens, P., De Gelder, B., Weiskrantz, L., \& Goebel, R. (2012). Subcortical connections to human amygdala and changes following destruction of the visual cortex. Current Biology. https://doi.org/10.1016/j.cub.2012.06.006

Thielscher, A., Opitz, A., \& Windhoff, M. (2011). Impact of the gyral geometry on the electric field induced by transcranial magnetic stimulation. NeuroImage. https://doi.org/10.1016/ j.neuroimage.2010.07.061

Trevethan, C. T., Sahraie, A., \& Weiskrantz, L. (2007). Can blindsight be superior to "sightedsight"? Cognition. https://doi.org/10.1016/j.cognition.2006.04.011

Vanrullen, R. (2007). The power of the feed-forward sweep. Advances in Cognitive Psychology. https://doi.org/10.2478/v10053-008-0022-3

VanRullen, R., \& Koch, C. (2003). Visual selective behavior can be triggered by a feed-forward process. Journal of Cognitive Neuroscience. https://doi.org/10.1162/089892903321208141

Warner, C. E., Kwan, W. C., Wright, D., Johnston, L. A., Egan, G. F., \& Bourne, J. A. (2015). Preservation of vision by the pulvinar following early-life primary visual cortex lesions. Current Biology. https://doi.org/10.1016/j.cub.2014.12.028

Weise, K., Numssen, O., Thielscher, A., Hartwigsen, G., \& Knösche, T. R. (2020). A novel approach to localize cortical TMS effects. NeuroImage. https://doi.org/10.1016/ j.neuroimage.2019.116486

Weiskrantz, Larry. (2009). Is blindsight just degraded normal vision? In Experimental Brain Research. https://doi.org/10.1007/s00221-008-1388-7

Weiskrantz, Lawrence, Cowey, A., \& Hodinott-Hill, I. (2002). Prime-sight in a blindsight subject. Nature Neuroscience. https://doi.org/10.1038/nn793

Weiskrantz, Lawrence, Warrington, E. K., Sanders, M. D., \& Marshall, J. (1974). Visual capacity in the hemianopic field following a restricted occipital ablation. Brain, 97(4), 709-728. https:// doi.org/10.1093/brain/97.4.709

White, B. J., Kan, J. Y., Levy, R., Itti, L., \& Munoz, D. P. (2017). Superior colliculus encodes visual saliency before the primary visual cortex. Proceedings of the National Academy of Sciences of the United States of America. https://doi.org/10.1073/pnas.1701003114

Wilson, C. L., Babb, T. L., Halgren, E., \& Crandall, P. H. (1983). Visual receptive fields and response properties of neurons in human temporal lobe and visual pathways. Brain. https:// doi.org/10.1093/brain/106.2.473

Wurtz, R. H., Richmond, B. J., \& Judge, S. J. (1980). Vision during saccadic eye movements. III. Visual interactions in monkey superior colliculus. Journal of Neurophysiology. https://doi.org/ 10.1152/jn.1980.43.4.1168

Yukie, M., \& Iwai, E. (1981). Direct projection from the dorsal lateral geniculate nucleus to the prestriate cortex in macaque monkeys. Journal of Comparative Neurology. https://doi.org/ 10.1002/cne.902010107

Zihl, J. (1980). "Blindsight": Improvement of visually guided eye movements by systematic practice in patients with cerebral blindness. Neuropsychologia. https://doi.org/ 10.1016/0028-3932(80)90085-8 